\title{
3-Dimensional Ultrasound: How can the Fetal Corpus Callosum Be Demonstrated Correctly?
}

\section{3-dimensionaler Ultraschall: Wie stellt man das fetale Corpus callosum korrekt dar?}

Authors

Sonila Pashaj, Eberhard Merz

Affiliation

Center for Ultrasound and Prenatal Medicine Frankfurt, Frankfurt am Main, Germany

Key words

fetus, corpus callosum, 3D ultrasound, how to

received 11.05 .2020

accepted 12.01.2021

published online 22.02.2021

Bibliography

Ultraschall in Med 2021; 42: 278-284

DOI 10.1055/a-1365-8611

ISSN $0172-4614$

(C) 2021. Thieme. All rights reserved.

Georg Thieme Verlag KG, Rüdigerstraße 14,

70469 Stuttgart, Germany

Correspondence

Dr. Sonila Pashaj

Center for Ultrasound and Prenatal Medicine Frankurt, Ebersheimstr. 5, 60320 Frankfurt, Gemany

Tel.: ++ 496976806559

Fax: ++496976806631

sonila_pashaj@hotmail.com

\section{ABSTRACT}

The aim of this article is to outline the correct demonstration of the fetal corpus callosum with 3D ultrasound between 18 and 40 weeks of gestation. An abdominal or transvaginal 3D transducer can be used for acquisition of the fetal brain depending on the position of the fetus. The best demonstration of the corpus callosum can be achieved, when the volume with the corpus callosum is acquired from a sagittal or parasagittal sectional plane of the brain. Once the volume is stored in the memory, the multiplanar mode allows manipulation in all three dimensions until the exact median plane is seen, showing the corpus callosum as a hypo- or anechoic curved structure. Volume acquisition of the brain from an axial plane of the fetal head - typically used for biometrical measurements of the head diameters - is not recommended for clinical evaluation of the corpus callosum because the reconstruc- ted median plane does not reveal the margins and the structure of the corpus callosum precisely. Other display modes such as volume contrast imaging ( $\mathrm{VCl})$, OmniView$\mathrm{VCl}$, and tomographic display may also be used for demonstration of the corpus callosum. However, these display modes only provide the operator with good image quality of the corpus callosum if the fetal brain was acquired from a sagittal and not from an axial plane.

Conclusion 3D ultrasound is an excellent clinical tool for the exact presentation of the fetal corpus callosum because it allows volume manipulation of the fetal head in all three dimensions with precise demonstration of the median plane of the brain.

\section{ZUSAMMENFASSUNG}

Das Ziel dieses Artikels ist es, einen Überblick über die korrekte Demonstration des fetalen Corpus callosum mittels 3D-Ultraschall zwischen 18 und 40 Schwangerschaftswoche zu geben. Je nach Lage des Fötus kann für die Aufnahme des fetalen Gehirns ein abdominaler oder transvaginaler 3D-Schallkopf verwendet werden. Die beste Darstellung des Corpus callosum kann erreicht werden, wenn das Volumen mit dem Corpus callosum aus einer sagittalen oder parasagittalen Schnittebene des Gehirns aufgenommen wird. Sobald das Volumen im Speicher abgelegt ist, ermöglicht der multiplanare Modus die Manipulation in allen 3 Dimensionen, bis die exakte Medianebene zu sehen ist, die das Corpus callosum als eine hypo- oder anechogene gekrümmte Struktur zeigt. Die Volumenerfassung des Gehirns aus einer axialen Ebene des fetalen Kopfes - typischerweise für biometrische Messungen der Kopfdurchmesser verwendet - wird für die klinische Beurteilung des Corpus callosum nicht empfohlen, da die rekonstruierte Medianebene die Ränder und die Struktur des Corpus callosum nicht exakt erkennen lässt. Andere Darstellungsmodi wie $\mathrm{VCl}$ (Volume Contrast Imaging), OmniView$\mathrm{VCl}$ und die tomografische Darstellung können ebenfalls zur Demonstration des Corpus callosum verwendet werden. Diese Darstellungsmodi bieten dem Untersucher jedoch nur dann eine gute Bildqualität des Corpus callosum, wenn das fetale Gehirn aus einer sagittalen und nicht aus einer axialen Ebene aufgenommen wurde. 
Schlussfolgerung 3D-Ultraschall ist ein ausgezeichnetes klinisches Werkzeug für die exakte Demonstration des fetalen Corpus callosum, da er eine Volumenmanipulation des fetalen
Kopfes in allen 3 Dimensionen mit präziser Darstellung der Medianebene des Gehirns ermöglicht.

\section{Background}

The corpus callosum is the largest telencephalic commissure which enables the communication between the left and right hemisphere of the brain [1]. It is therefore an important anatomical landmark for the evaluation of normal fetal brain development [2-4].

In prenatal diagnosis the occurrence of corpus callosum pathologies is significantly underestimated. While a large number of studies on fetal agenesis of the corpus callosum [5-10] has been published, reports on the diagnosis of partial agenesis, hypoplasia, and hyperplasia of the corpus callosum are scarce [11, 12]. The described malformations require not only a precise demonstration of the corpus callosum in the median plane of the fetal brain but also exact knowledge of the normal reference ranges of the prenatal corpus callosum lengths and heights of the different anatomical parts [11].

In comparison to 2D ultrasound, 3D sonography allows a more precise demonstration of the corpus callosum due to the fact that the median plane can be controlled by the two perpendicular planes and corrected with the rotation controls.

However, there are conflicting data in the literature regarding the ultrasound appearance of the corpus callosum by means of 2D and 3D ultrasound. 2D studies have described the corpus callosum as a hypoechoic structure $[2,13]$, while in the $3 \mathrm{D}$ mid-sagittal plane reconstructed from volumes acquired in axial planes, the corpus callosum has been defined as a hyperechoic structure [14-17].

The aim of the present article is to outline the correct approach to volume acquisition of the fetal brain that allows an accurate demonstration and evaluation of the corpus callosum.

\section{Practical points}

\section{D and 3D ultrasound appearance of the corpus callosum}

Using either 2D or 3D ultrasound, the corpus callosum is correctly displayed as an anechoic to hypoechoic curved band between the gyrus cinguli superiorly and the cavum septi pellucidi and the cavum vergae inferiorly and is demarcated by two echogenic lines [12] ( $\triangleright$ Fig. 1a, b). Normal development of the corpus callosum confirmed by ultrasound requires measurement of the corpus callosum length (outer-outer, inner-inner, or curved length) as well as of the height of each of the four anatomical parts (rostrum, genu, body, and splenium) [12].

\section{Why is 3D sonography superior to 2D ultrasound in the demonstration of the corpus callosum?}

Both 2D and 3D ultrasound use the same acoustic windows for the demonstration of the brain anatomy and all scanning planes emerge from a single point in the acoustic window. In 2D ultrasound the probe must be moved manually to visualize different planes, while in $3 \mathrm{D}$ probes the scanning plane is moved automatically in a fan-like fashion enabling the acquisition of a volume in the shape of a truncated pyramid [3]. From this volume all planes, oblique and parallel ones, can be reconstructed by volume manipulation.

In most fetuses in breech position and transverse lie, the exact midsagittal plane of the fetal head is technically difficult to obtain with standard 2D transabdominal ultrasound [18]. In fetuses with vertex presentation, transvaginal sonography is the technique of choice for fetal neurosonography [10, 12]. However, using $2 \mathrm{D}$ ultrasound, there is no control regarding the exact median plane.

There are several advantages of three-dimensional ultrasound over two-dimensional imaging for the visualization of the corpus callosum:

1. 3D ultrasound enables volume acquisition of the brain also in difficult positions of the fetal head. The corpus callosum can be shown in an exact midsagittal plane ( $\bullet$ Fig. 2 ) by manipulating the stored volume using the rotation controls. The two perpendicular planes allow exact control of the median plane. Such control is not available with 2D ultrasound.

2. 3D ultrasound facilitates the correct anatomical orientation in the fetal brain and the demonstration of the entire corpus callosum. As a three-dimensional curved structure, the corpus callosum should be assessed in all three orthogonal planes: the sagittal, the axial, and the coronal. The multiplanar mode enables correct anatomical orientation within the volume by using the midline structures of the fetal brain such as the interhemispheric fissure, the cavum septi pellucidi, the cavum vergae, and vermis cerebelli in all three planes ( $>$ Fig. 2 ).

3. The 3D ultrasound surface mode and the $\mathrm{VCl}$ mode enhance the brain structures and thus the image quality.

4. 3D ultrasound reduces the examination time.

5. 3D ultrasound facilitates the demonstration of the corpus callosum by less experienced operators.

6 . The possibility to store volumes digitally without any quality loss, allows reloading and manipulation of each volume by different experts in different display modes.

\section{Position of the fetus and the mother}

In fetuses with vertex presentation, transvaginal sonography is recommended for the demonstration of the corpus callosum. The maternal bladder should be empty to reduce the distance 


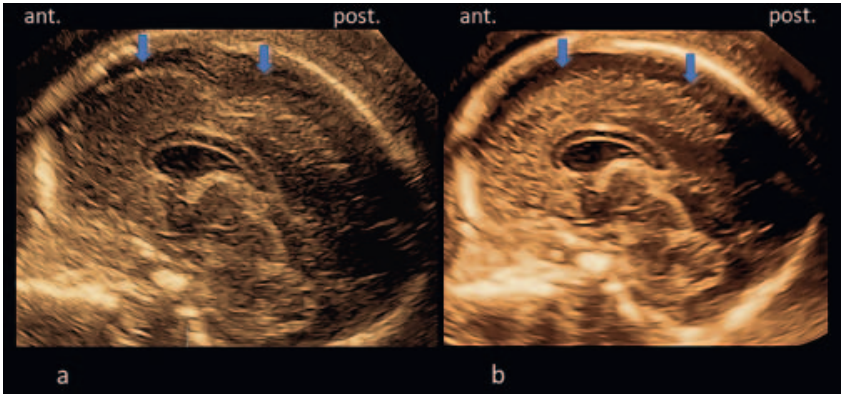

- Fig. 1 a Transvaginally acquired 2D image of a fetal brain at 20 weeks of gestation. The corpus callosum is demonstrated as a hypoechoic structure. However, the irregular appearance of the brain surface (arrows) indicates that the 2D image does not show a correct median plane. $\mathbf{b}$ Transvaginally acquired 3D ultrasound volume of the fetal brain at 20 gestational weeks, demonstrating the surface rendered image of an exact midsagittal plane with regular appearance of the brain surface (arrows). As in 2D ultrasound the corpus callosum is shown as a hypoechoic structure. ant. = anterior, post. $=$ posterior.

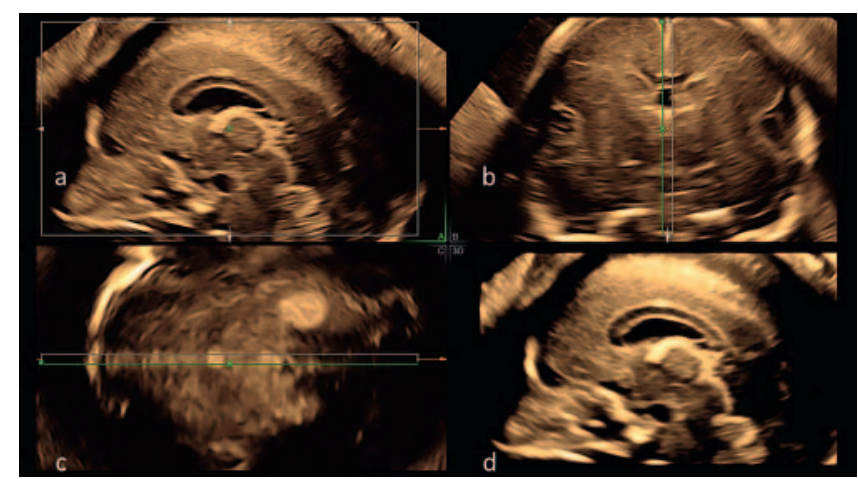

- Fig. 2 Multiplanar and surface rendered demonstration of the fetal brain (21 weeks of gestation). a Median plane, showing the hypoechoic corpus callosum, $\mathbf{b}$ coronal plane, and $\mathbf{c}$ axial plane. d Surface rendered image of the median plane with the corpus callosum.

between the probe and the corpus callosum. In fetuses with breech presentation or transverse lie, an abdominal 3D probe is used. In vertex presentation the demonstration of the corpus callosum is also feasible with the transabdominal probe, however only if the fetal head is not deeply engaged in the pelvis. In cases of asynclitism of the fetal head, manipulation from the abdominal site with the free hand of the operator is recommended to bring the head into a more favorable position. If the fetus is in breech or transverse presentation, rotation of the mother to her right or left side may permit an optimal position of the anterior fontanelle to be used as an acoustic window. In breech presentation a sitting position of the mother ( $\vee$ Fig. 3 ) may be helpful to demonstrate the corpus callosum exactly.

Volume acquisition of the corpus callosum is performed in the absence of fetal movements or maternal breathing.

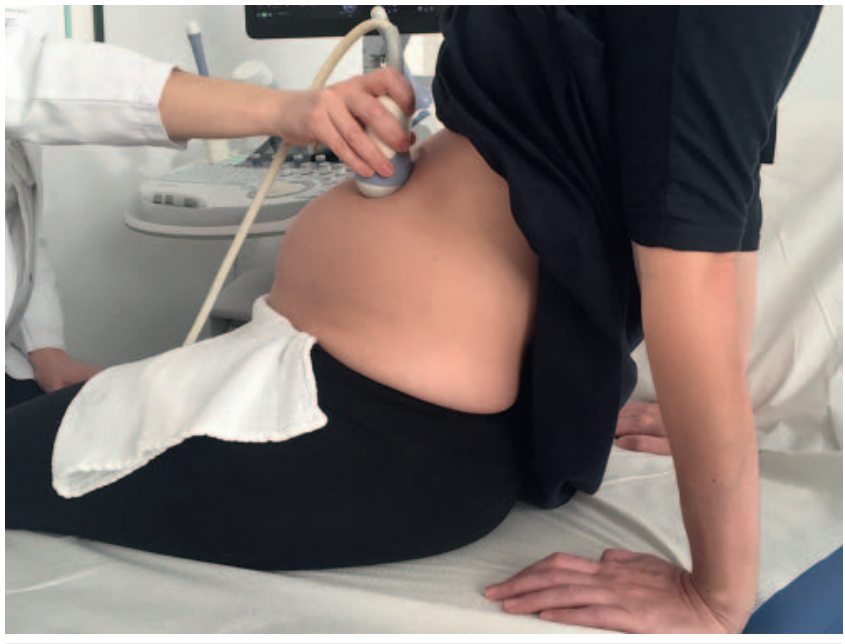

- Fig. 3 Demonstration of the volume acquisition of the fetal brain with the mother in a sitting position when the fetus is in a difficult breech presentation.

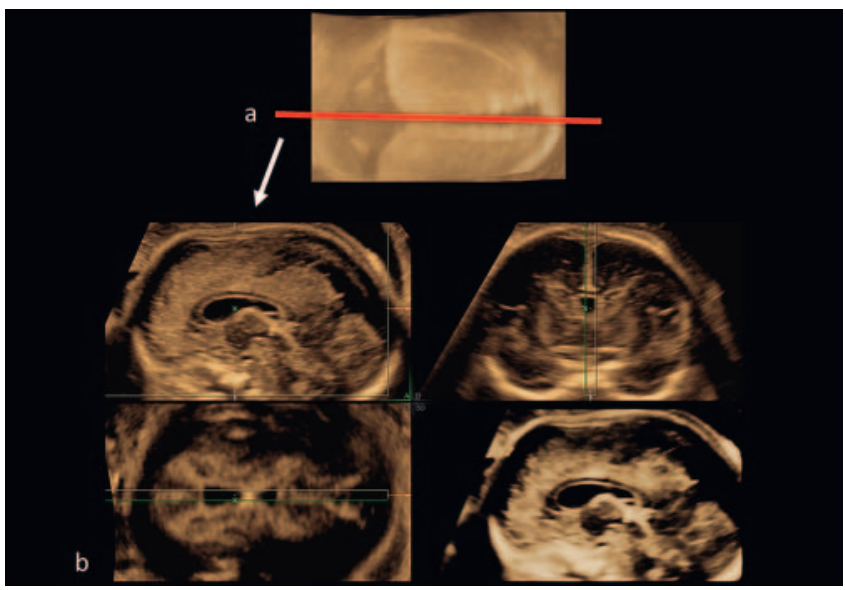

- Fig. 4 a Volume acquisition of the fetal brain: the sagittal suture is used as an acoustic window (red line). b 3D volume of the fetal brain acquired from the sagittal suture which allows correct demonstration of the corpus callosum.

\section{What are the best acoustic windows for the demonstration of the corpus callosum?}

In the second trimester, depending on the fetal position, the volume of the corpus callosum can be acquired with the abdominal or transvaginal 3D transducer, using either the anterior fontanelle or the sagittal suture as an acoustic window like in $2 \mathrm{D}$ ultrasound ( $\triangleright$ Fig. $4 a$ ). This enables the reconstruction of sagittal, parasagittal, coronal, and oblique planes of the fetal brain $[4,19]$ ( $\vee$ Fig. $\mathbf{4 b}$ ). In the third trimester the corpus callosum is better visualized from the anterior fontanelle in the sagittal plane due to the reduction of suture width. The lambdoid suture and posterior fontanelle do not allow clear visualization of the rostrum and genu, whereas the metopic suture does not provide information on the posterior part of the body and the splenium. The sphenoid and mastoid fontanelle or the coronal and lambdoid suture are 
not recommended for volume acquisition to demonstrate the corpus callosum.

\section{Is it important to visualize the entire corpus callosum before volume acquisition?}

$2 \mathrm{D}$ visualization of the entire corpus callosum is not mandatory prior to volume acquisition. It is of greater importance to ascertain that all parts of the corpus callosum are visualized during the process of volume acquisition. To include most of the brain in the volume, the sweep angle for the volume acquisition must be set at least between $45^{\circ}$ and $80^{\circ}$ depending on the gestational age. However, this is difficult to achieve in the late third trimester.

Once the brain volume containing the corpus callosum is acquired, the three perpendicular planes can be corrected with the use of the rotation controls, until the corpus callosum is seen in the correct median plane.

\section{Which are the most suitable scanning planes to acquire the volume?}

The best demonstration of the corpus callosum is possible when the brain volume is acquired from a sagittal or parasagittal plane or from the three-horn view $(\triangleright$ Fig. $\mathbf{1}, \mathbf{2}$ ). This requires only a small volume angle with a low risk of motion artifacts and enables the highest image quality. Acquisition from a coronal plane may be possible in a limited number of cases in the second trimester ( $\triangleright$ Fig. 5). However, a high-volume angle is necessary to include the entire corpus callosum. This increases the risk of motion artifacts during volume acquisition. Furthermore, acquisition from a coronal plane is not achievable in the third trimester due to the narrowing of the sutures and anterior fontanelle and the increased length of the corpus callosum. Therefore, acquisition from a coronal plane is not recommended for daily routine applications.

\section{Which planes are NOT recommended to use for the acquisition of a volume to demonstrate the corpus callosum?}

Volume acquisition of the corpus callosum from an axial plane of the fetal head is not recommended because the median plane always remains a reconstructed plane with low image quality and shows the corpus callosum incorrectly as a hyperechoic structure ( $\triangleright$ Fig.6). Even if the volume acquired from the axial plane of the fetal head is examined with different 3D display modes such as $\mathrm{VCl}$, tomographic display ( $>$ Fig. 7), OmniView-VCI ( $\mathbf{F i g . 8}$.), or the surface mode, the $C$-plane always remains a reconstructed one which does not allow an exact diagnostic evaluation of the normal and abnormal corpus callosum ( $\triangleright$ Fig. 9). The appearance of corpus callosum as a hyperechoic structure may be due to the simultaneous use of 3D voxel reconstruction in conjunction with speckle reduction imaging (SRI) and represents the interface between the cingulated gyrus, the cingulated sulcus, cerebrospinal fluid, and the blood flow in the callosal arteries [20].

A true hyperechoic corpus callosum is only seen in cases of corpus callosum lipoma.

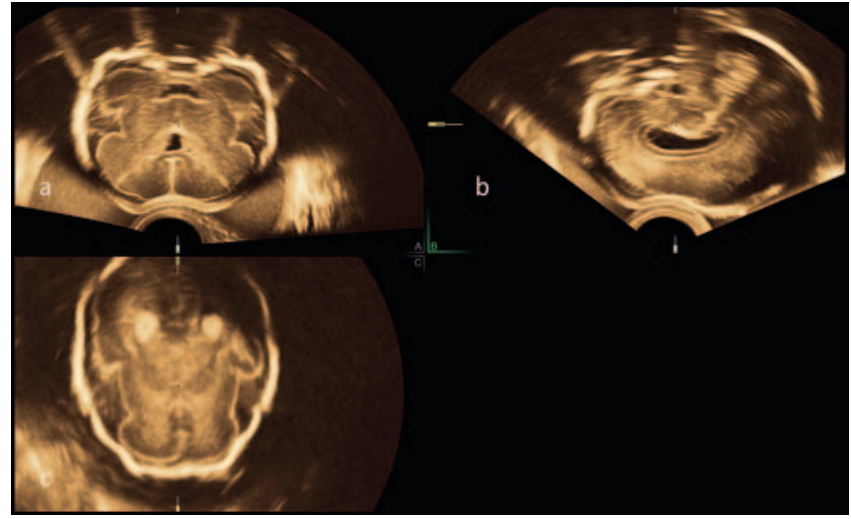

- Fig. 5 Transvaginal 3D ultrasound volume of the fetal brain at 26 gestational weeks, acquired from the coronal plane using a sweep angle of $120^{\circ}$ that includes the entire brain for visualization of the whole corpus callosum. a coronal plane, $\mathbf{b}$ sagittal plane, $\mathbf{c}$ axial plane.

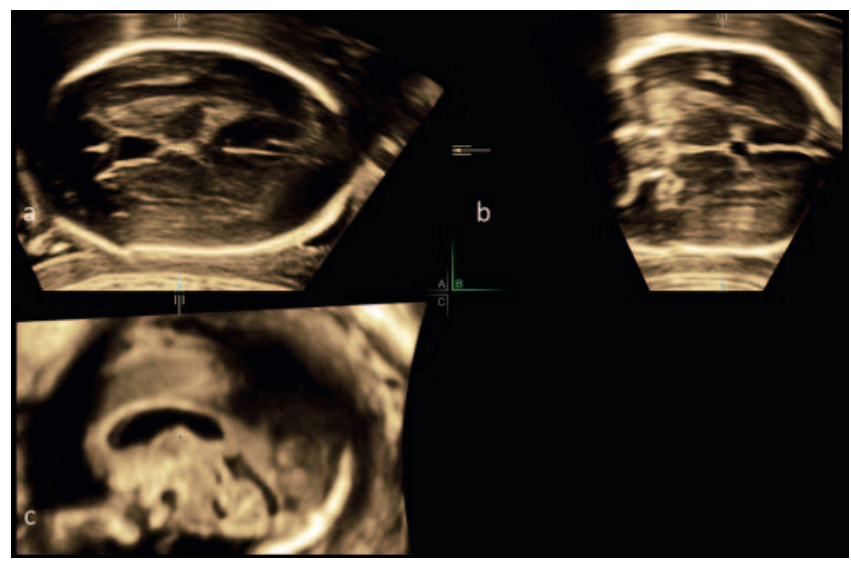

- Fig. 6 3D acquisition of the fetal brain from an axial plane. The reconstructed mid-sagittal plane does not allow a clear evaluation of the corpus callosum that is erroneously depicted as a hyperechoic structure. a axial plane, b coronal plane, $\mathbf{c}$ sagittal plane.

\section{How to manipulate the volume for the demonstration of the corpus callosum}

Once the volume containing the corpus callosum is acquired from a sagittal or parasagittal plane and stored in the memory of the ultrasound device, the three orthogonal planes can be manipulated by rotation and/or translation maneuvers in the multiplanar display mode to achieve the standard orientation ( $\triangleright$ Fig. 10a) of the corpus callosum. The sagittal plane is displayed in plane A, the coronal plane is depicted in plane $\mathrm{B}$, and the axial plane in plane $C$.

The reference dot is placed in the interhemispheric fissure in the coronal plane ( $\triangleright$ Fig. 10b) and the coronal plane is rotated about the $Z$ axis until the interhemispheric fissure is seen in an exact vertical orientation ( $\triangleright$ Fig. 10c). Then the axial plane $C$ has to be rotated about the reference dot until the interhemispheric fissure is seen in an exact horizontal position ( $\triangleright$ Fig. 10d). In this manner, plane $A$ reveals the exact median plane with the entire corpus callosum. This plane enables the operator also to observe 


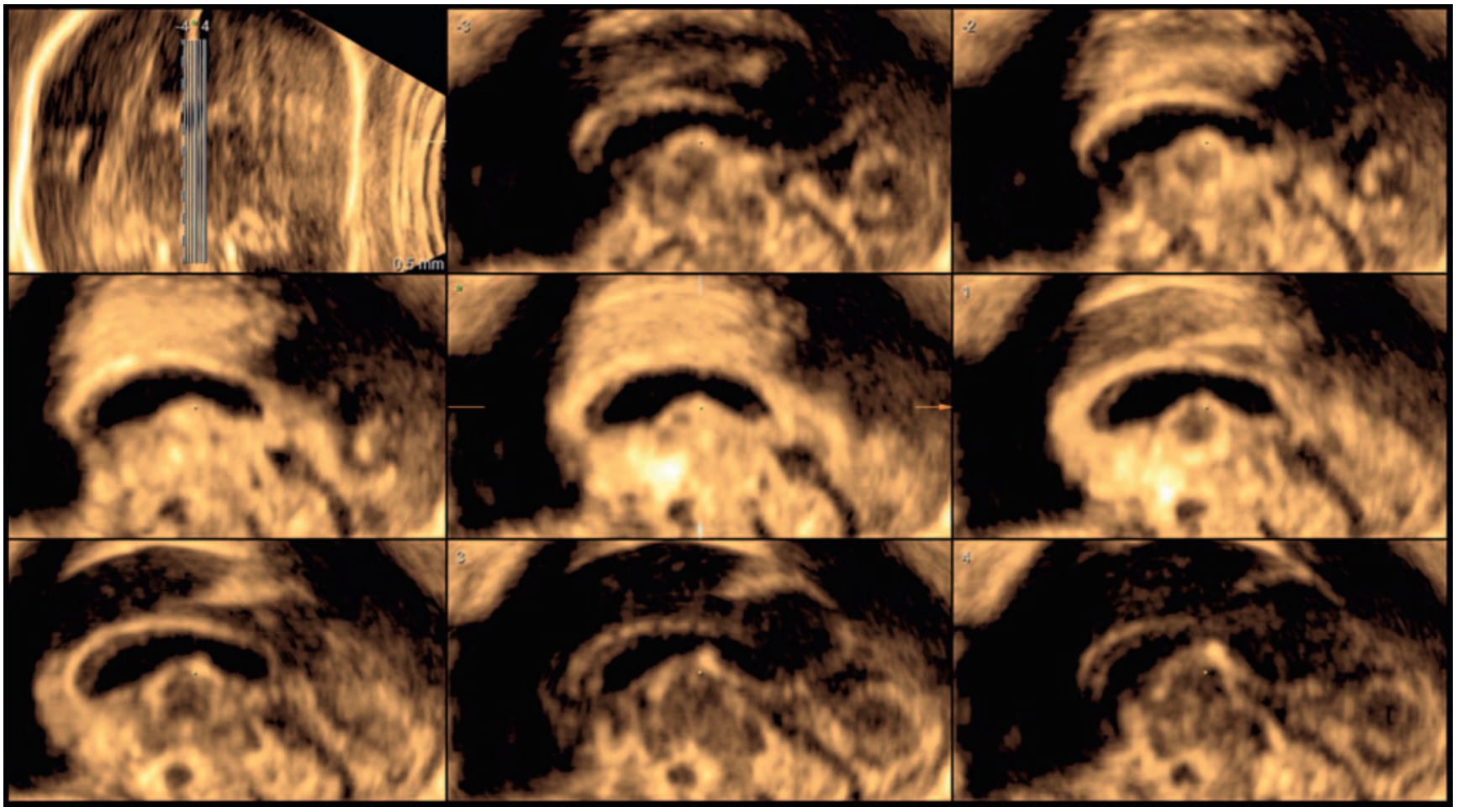

- Fig. 7 Tomographic demonstration of the same volume as in $>$ Fig. 6. Also, in this mode the corpus callosum has a hyperechoic appearance and does not show all its anatomical parts.

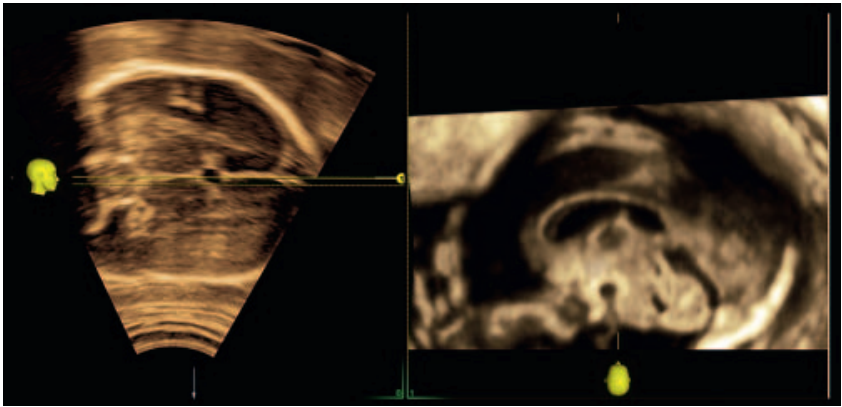

- Fig. 8 The same volume of the fetal brain as in $>$ Fig. 6, 7 displayed with OmniView mode showing the corpus callosum as a hyperechoic structure.

other anatomical structures such as the cavum septi pellucidi, the head of the caudate nucleus, the thalamus, parts of the midbrain, the cerebellar vermis, cisterna magna as well as the third and fourth ventricle ( $\nabla$ Fig. 10d). Once the entire corpus callosum is correctly demonstrated in the multiplanar mode, surface reconstruction of the median plane can be performed.

Throughout the entire prenatal period, the corpus callosum is sonographically correctly displayed as an anechoic or hypoechoic structure with clear demarcation from the cavum septi pellucidi and cavum vergae [12]. The four different structural parts of the corpus callosum, i.e., the rostrum, the genu, the body, and the splenium ( $\triangleright$ Fig. 10e) [12] can be assessed in the median plane. The rostrum has been defined as a beak-shaped segment curving

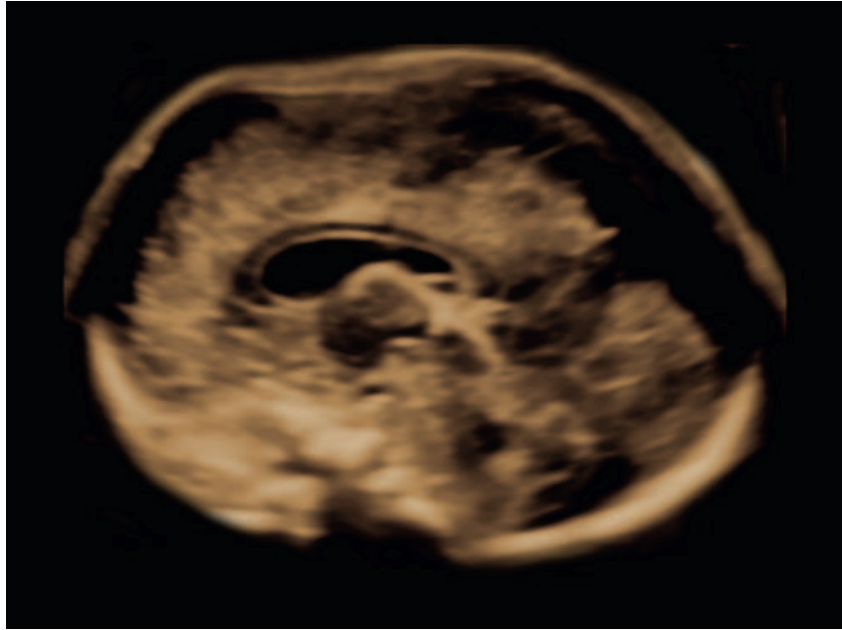

- Fig. 9 The same case as in $>$ Fig. 6-8. The volume is acquired from a parasagittal plane. After rotating the volume with the rotation controls, the exact median plane can be displayed, showing the corpus callosum with its four anatomical parts as a hypoechoic structure in the surface rendered image.

posteriorly or posteroinferiorly from the genu. The genu has been described as the curved anterior portion of the corpus callosum [12]. The body has been defined as the hypoechoic linear horizontal structure of the corpus callosum, while the splenium represents the caudally oriented posterior portion. 


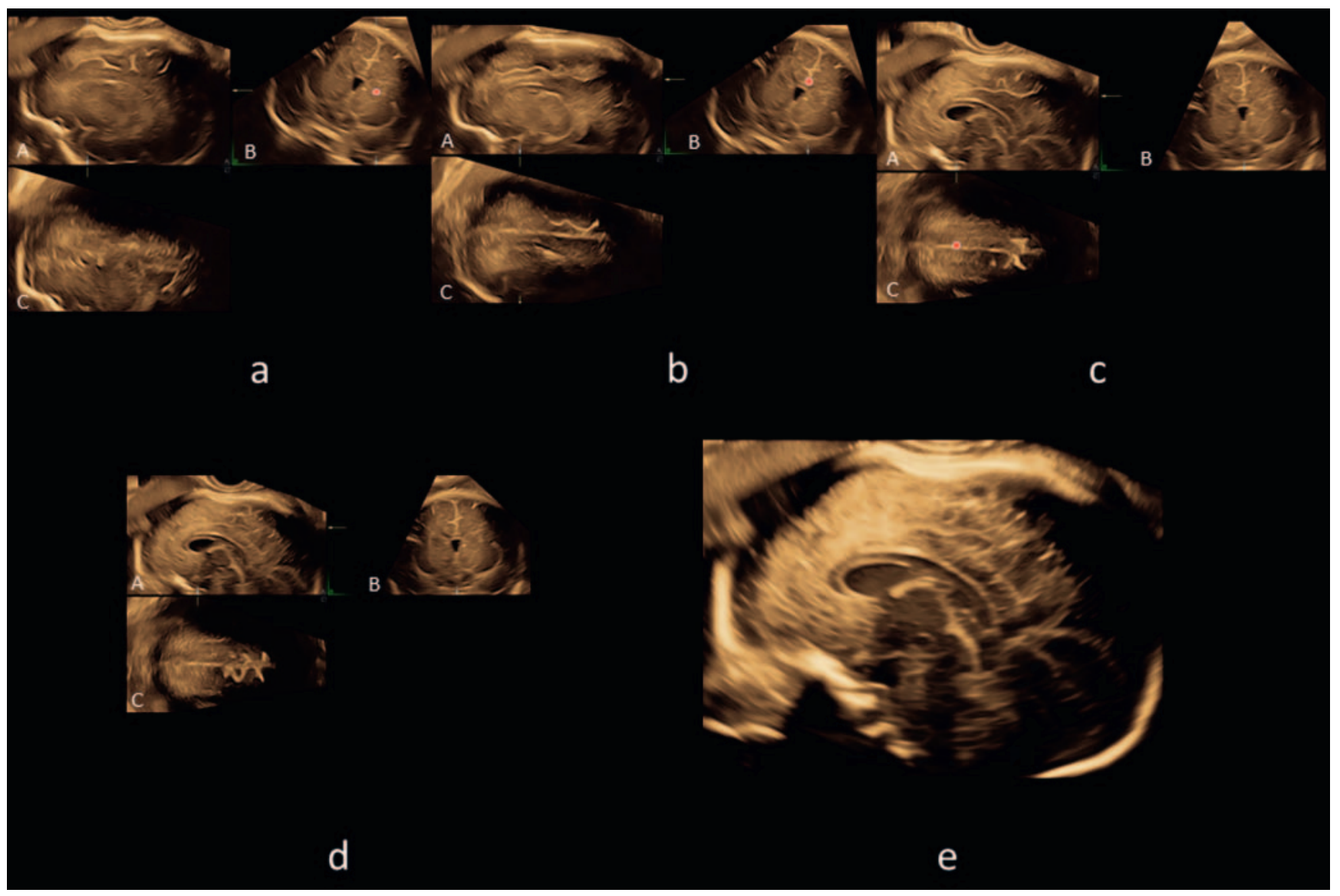

- Fig. 10 a Volume of the fetal brain acquired transvaginally from the three-horn view, demonstrating the three orthogonal planes. 31 weeks of gestation. b Plane A displays the parasagittal plane of the brain, plane B demonstrates the coronal plane and plane $C$ displays the axial plane. The reference dot is now placed in the interhemispheric fissure in the coronal plane. $\mathbf{c}$ The coronal plane is rotated about the $\mathrm{Z}$ axis until the interhemispheric fissure is seen in an exact vertical orientation. $\mathbf{d}$ Demonstration of the rotation of the axial plane $\mathrm{C}$ until the interhemispheric fissure is in an exact horizontal position. In this manner, plane A reveals the exact median plane with the entire corpus callosum. e Surface rendered image of the median plane with the entire corpus callosum as a hypoechoic structure.

\section{Conclusion}

3D ultrasound is an excellent clinical tool to demonstrate the fetal corpus callosum precisely. The anterior fontanelle serves as the best acoustic window for the demonstration of the corpus callosum. The volume with the corpus callosum should be acquired from a sagittal or parasagittal sectional plane of the brain. Once the volume has been stored in the memory of the ultrasound machine, the multiplanar mode enables the operator to correct planes in all three dimensions. After the exact demonstration of the median plane, the corpus callosum is seen as a hypo- or anechoic structure. The reconstructed midsagittal plane derived from the axial planes of the fetal head is not recommended for clinical evaluation of the corpus callosum because it does not allow a clear delineation of the corpus callosum and therefore no correct detection of corpus callosum abnormalities.

\section{Conflict of Interest}

The authors declare that they have no conflict of interest.

\section{References}

[1] Raybaud C. The corpus callosum, the other great forebrain commissures, and the septum pellucidum: anatomy, development, and malformation. Neuroradiology 2010; 52: 447-477

[2] Achiron R, Achiron A. Development of the human fetal corpus callosum: a high-resolution, cross-sectional sonographic study. Ultrasound Obstet Gynecol 2001; 18: 343-347

[3] Merz E. Targeted depiction of the fetal corpus callosum with 3D-ultrasound. Ultraschall in Med 2010; 31: 441

[4] Pashaj S, Merz E. Detection of fetal corpus callosum abnormalities by means of 3D Ultrasound. Ultraschall in Med 2016; 37: 194-195

[5] Pisani F, Bianchi ME, Piantelli G et al. Prenatal diagnosis of agenesis of corpus callosum: what is the neurodevelopmental outcome? Pediatr Int 2006; 48: 298-304

[6] Moutard ML, Kieffer V, Feingold J et al. Isolated corpus callosm agenesis: a ten-year follow-up after prenatal diagnosis [how are the children without corpus callosum at 10 years of age?]. Prenat Diagn 2012; 32: 277-283 
[7] Moutard ML, Kieffer V, Feingold J et al. Agenesis of corpus callosum: prenatal diagnosis and prognosis. Childs Nerv Syst 2003; 19: 471-476

[8] Pilu G, Sandri F, Perolo A et al. Sonography of fetal agenesis of the corpus callosum: a survey of 35 cases. Ultrasound Obstet Gynecol 1993; 3: 318 329

[9] Comstock CH, Culp D, Gonzalez J et al. Agenesis of the corpus callosum in the fetus: its evolution and significance. J. Ultrasound in Med 1985; 4: 613-616

[10] D’Addario V, Pinto V, Di Cagno L et al. The midsagittal view of the fetal brain: a useful landmark in recognizing the cause of fetal cerebral ventriculomegaly. J Perinat Med 2005; 33: 423-427

[11] Pashaj S, Merz E. Assessment of corpus callosum development by use of 3D ultrasound. Ultrasound Obstet Gynecol 2012; 40: 22

[12] Pashaj S, Merz E, Wellek S. Biometry of the fetal corpus callosum by three-dimensional ultrasound. Ultrasound Obstet Gynecol 2013; 42: 691-698

[13] Malinger G, Zakut H. The corpus callosum: Normal Fetal development as shown by transvaginal sonography. Am J Roentgenol 1993; 161: 10411043
[14] Correa FF, Lara C, Bellver ] et al. Examination of the fetal brain by transabdominal three dimensional ultrasound: potential for routine neurosonographic studies. Ultrasound Obstet Gynecol 2006; 27: 503-508

[15] Pilu G, Segata M, Ghi T et al. Diagnosis of midline anomalies of the fetal brain with the three- dimensional median view. Ultrasound Obstet Gynecol 2006; 27: 522-529

[16] Rizzo G, Pietrolucci ME, Capponi A et al. Assessment of corpus callosum Biometric measurement at 18 to 32 weeks'gestation by 3-dimensional sonography. J Ultrasound Med 2011; 30: 47-53

[17] Youssef A, Ghi T, Pilu G. How to image the fetal corpus callosum. Ultrasound Obstet Gynecol 2013; 42: 718-720

[18] Pilu G, De Palma L, Romero R et al. The fetal subarachnoid cisterns. An ultrasound study with report of a case of congenital communicating hydrocephalus. J Ultrasound Med 1986; 5: 365-372

[19] Bornstein E, Monteagudo A, Santos R et al. A systematic technique using 3-dimensional ultrasound provides a simple and reproducible mode to evaluate the corpus callosum. Am J Obstet Gynecol 2010; 202: 201.e1201.e5

[20] Malinger G, Lerman-Sagie T, Viñals F. Three-dimensional sagittal reconstruction of the corpus callosum: fact or artifact? Ultrasound Obstet Gynecol 2006; 28: 742-743 